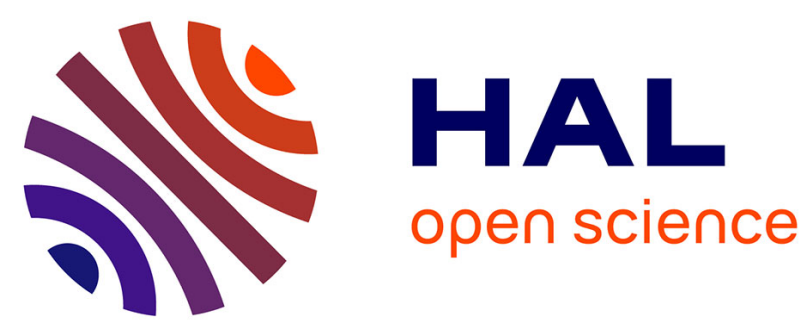

\title{
Problematic non-double-couple mechanism of the 2002 Amfilochia M5 earthquake, Western Greece
}

\author{
Petra Adamova, Efthimios Sokos, Jiri Zahradnik
}

\section{To cite this version:}

Petra Adamova, Efthimios Sokos, Jiri Zahradnik. Problematic non-double-couple mechanism of the 2002 Amfilochia M5 earthquake, Western Greece. Journal of Seismology, 2008, 13 (1), pp.1-12. 10.1007/s10950-008-9112-4 . hal-00478433

\section{HAL Id: hal-00478433 \\ https://hal.science/hal-00478433}

Submitted on 30 Apr 2010

HAL is a multi-disciplinary open access archive for the deposit and dissemination of scientific research documents, whether they are published or not. The documents may come from teaching and research institutions in France or abroad, or from public or private research centers.
L'archive ouverte pluridisciplinaire HAL, est destinée au dépôt et à la diffusion de documents scientifiques de niveau recherche, publiés ou non, émanant des établissements d'enseignement et de recherche français ou étrangers, des laboratoires publics ou privés. 


\title{
Problematic non-double-couple mechanism of the 2002 Amfilochia $M_{w} 5$ earthquake, Western Greece
}

\author{
Petra Adamova $\cdot$ Efthimios Sokos • Jiri Zahradnik
}

Received: 19 March 2007 / Accepted: 13 May 2008 / Published online: 27 June 2008

(C) Springer Science + Business Media B.V. 2008

\begin{abstract}
Two seismic agencies reported a very low double-couple percentage (DC\%) of the Amfilochia earthquake, of about $30 \%$ and $60 \%$, by Schweizerischer Erdbebendienst and Mediterranean Very Broadband Seismographic Network, respectively. Near-regional waveforms, carefully analyzed in this paper for the $\mathrm{DC} \%$, suggested a higher $\mathrm{DC} \%$, ranging from 75 to 100 , dependent on the uncertainty of the source position (optimum value $\mathrm{DC} \%=93$ ). Using a statistical $F$ test, forward modeling of the near-regional data with a single-event low-DC\% source yields a significantly worse waveform match. The fit of
\end{abstract}

P. Adamova $(\varangle)$

Academy of Sciences, Institute of Geophysics,

Prague, Czech Republic

e-mail: adamova@ig.cas.cz

E. Sokos

Seismological Laboratory, University of Patras,

Patras, Greece

e-mail: esokos@upatras.gr

E. Sokos

Institute of Geodynamics,

National Observatory of Athens,

Athens, Greece

J. Zahradnik

Faculty of Mathematics and Physics,

Charles University,

Prague, Czech Republic

e-mail: jiri.zahradnik@mff.cuni.cz near-regional data can be further improved (although at the $90 \%$ significance level only) when considering a speculative two-event model. The same model, when viewed at the very-low frequency range, reaches the very low DC\% values. However, two features make the two-event model unlikely: The two subevents strongly differ in their focal mechanism, and their mutual separation (3.5 s) is larger than the expected duration of this earthquake. Therefore, the two-source model appears to be nothing but an interesting equivalent representation of the non-DC model, providing some insight into the possible origin of the apparently low DC\%. Preference is given to the simple interpretation, most clearly supported by the near-regional data, that the Amfilochia earthquake was an almost pure-shear event.

Keywords Moment tensor •

Iterative deconvolution - Regional data •

Waveform inversion - Deviatoric solution •

Source complexity $\cdot$ Focal mechanism

\section{Introduction}

Although moment tensor retrieval has become a routine task of seismological agencies, often even automated for real-time use (e.g., Bernardi et al. 2004; Pondrelli et al. 2006; Clinton et al. 2006; Rueda and Mezcua 2005; Pasyanos et al. 1996), 
detailed case studies show that the regional waveform inversion is far from being trivial. Several issues still deserve attention: the spatial and temporal resolution of the centroid, relations between the centroid and hypocenter, recognition of the fault plane, problematic interpretation of the nonDC part of the moment tensor, etc. In the present paper, we focus just on the last of them.

There has been an increasing interest in the non-DC events in recent years since classical review papers (Julian et al. 1998; Miller et al. 1998). It is because of their possible relation to interesting phenomena, mainly in volcanic, geothermal, and swarm regions, such as fluid motions, tensile cracks, anisotropy, and fault complexity (e.g., Dahm et al. 1999; Sarao et al. 2001; Horálek et al. 2002; Julian and Foulger 2004; Vavryčuk 2002, 2004; Roessler et al. 2006; Yunga et al. 2005). At the same time, many papers issue warnings about the correct physical interpretation of the non-DC components; some of them point out even difficulties in the reliable non-DC assessment itself, e.g., due to noise, poor station coverage, incomplete structural models, fault finiteness, misalignment of real and synthetic data, etc. (Frohlich 1994, 1995; Dahm et al. 1999; Jechumtálová and Šílený 2001; Bruhn 2003; Weber 2006; Hagos et al. 2006; Roessler et al. 2007; Vavrycuk 2007).

The aim of the present paper is to analyze a selected $\mathrm{M}_{\mathrm{w}} \sim 5$ earthquake in Western Greece, characterized by agency reports with a very large non-double-couple component. We perform waveform inversion at near-regional stations at frequencies $0.02-0.11 \mathrm{~Hz}$, carefully analyze the double-couple percentage of the moment tensor, and arrive at a much larger DC\% value than in the agency solutions. When modeling the nearregional data with the agency MT solution, the waveform match is worse. The same is true when artificially lowering the DC\% of our MT solution to the agency value of $30 \%$ (e.g., by introducing a 2-s shift of the origin time); the match is worse even at the $99 \%$ significance level. To interpret the $\mathrm{DC} \%$, a speculative two-point source model is designed. It is better than the single-point model but at the $90 \%$ significance level only. It features a frequency dependent DC\%, with the very lowfrequency value compares well with the agency reports of $\mathrm{DC} \%$. Both single- and two-point models are thoroughly discussed. Finally, the twoevent model is classified merely as an interesting equivalent to the low-DC agency solution, but the preference is given to the pure-shear interpretation of the Amfilochia earthquake.

\section{Data and method}

A moderate earthquake of $\mathrm{M}_{\mathrm{w}} \sim 5$ occurred on December 31, 2002, near the town of Amfilochia, eastern coast of the Gulf of Amvrakikos, Western Greece. For the earthquake location, see Table 1 and Fig. 1. They also include hypocenter determination specifically performed for this study. It resulted in the epicenter position very close to that of US Geological Survey (USGS). A very different and quite low percentage of the DC part, about $30 \%$ and $60 \%$, was reported by the Swiss Seismological Service (SED) ${ }^{1}$ and Mediterranean Very Broadband Seismographic Network (MEDNET; Table 2). Just this low DC\% is of major interest in the present paper. We shall investigate how the waveform simulations at nearregional stations contribute to explanation of the DC\% value.

Three-component seismograms were provided by the Institute of Geodynamics, National Observatory of Athens (NOA-IG). We use four stations of the NOA network (epicentral distances from 50 to $150 \mathrm{~km}$ ): EVR, JAN, RLS, and KEK equipped by Le-3D/20 s; for details, see Melis and Konstantinou (2006). Modeling is performed with full-wave (complete) green functions calculated by the discrete wave-number method (Bouchon 1981), using a 1D crustal model of the studied region derived by local earthquake tomography (Haslinger et al. 1999). The waveform inversion for the moment tensor is performed with the ISOLA code (Sokos and Zahradník 2008), using the frequency range $0.02-0.11 \mathrm{~Hz}$. The lower frequencies are not available due to long-period noise; the higher frequencies cannot be deterministically modeled in the available crustal models.

In ISOLA code, the moment tensor is calculated by minimizing the difference between the

\footnotetext{
${ }^{1}$ Schweizerischer Erdbebendienst, Swiss Seismological Service.
} 
Table 1 Location reported by three agencies and calculated in this paper

\begin{tabular}{lllll}
\hline Agency & $\begin{array}{l}\text { Origin time } \\
(\text { UTC) }\end{array}$ & $\begin{array}{l}\text { Lat. N } \\
(\mathrm{deg})\end{array}$ & $\begin{array}{l}\text { Lon. E } \\
(\mathrm{deg})\end{array}$ & $\begin{array}{l}\text { Depth } \\
(\mathrm{km})\end{array}$ \\
\hline PATNET & $20: 28: 32$ & 38.94 & 21.17 & 18 \\
USGS (NEIC) & $20: 28: 33$ & 39.00 & 21.25 & 18 \\
EMSC & $20: 28: 32$ & 39.14 & 20.94 & 2 \\
This paper & $20: 28: 33$ & 39.00 & 21.23 & 13 \\
\hline
\end{tabular}

The solution of this paper was calculated from the highquality manual picks of $\mathrm{P}$ and $\mathrm{S}$ waves at approximately 20 stations and the crustal model of Tselentis et al. (1996), routinely used for the earthquake location in Western Greece.

observed and synthetic displacement in the leastsquare sense at a set of predefined trial source positions and trial origin times. The grid search provides the best centroid position and time in terms of the absolute value of the correlation coefficient between the data and synthetics (for brevity called just the "correlation"). The match between the observed and best-fitting synthetic data is characterized by the overall variance reduction: varred $=1-\frac{E}{O}$, where $E=$
$\sum\left(O_{i}-S_{i}\right)^{2}, O=\sum O_{i}^{2}, O$ and $S$ standing for the observed and synthetic data, summation over all samples, components, and stations.

The deviatoric moment tensor is decomposed into its DC and non-DC (=CLVD) part of the relative size (1-2f) and (2f); where $1, \mathrm{f}-1$, and $-f$ are the normalized eigenvalues. The term 100* (1-2f) is referred to as the DC\%. The momenttensor solution can be repeated for subevents. Once the first subevent is found, its synthetic seismograms are subtracted from the observed seismograms, and the residual waveforms are processed analogously as the original ones (the so-called iterative deconvolution; Kikuchi and Kanamori 1991).

To compare several solutions quantitatively, we follow Pasyanos et al. (1996) using their parameter $\mu ; \mu$ between 0 and 0.25 holds for very similar fault plane solutions, $\mu>0.5$ is for highly dissimilar mechanisms.

To quantify whether model 1 gives a statistically significant improvement of the waveform match compared to another model 2, we use the $F$ test. Each model is characterized by its misfit

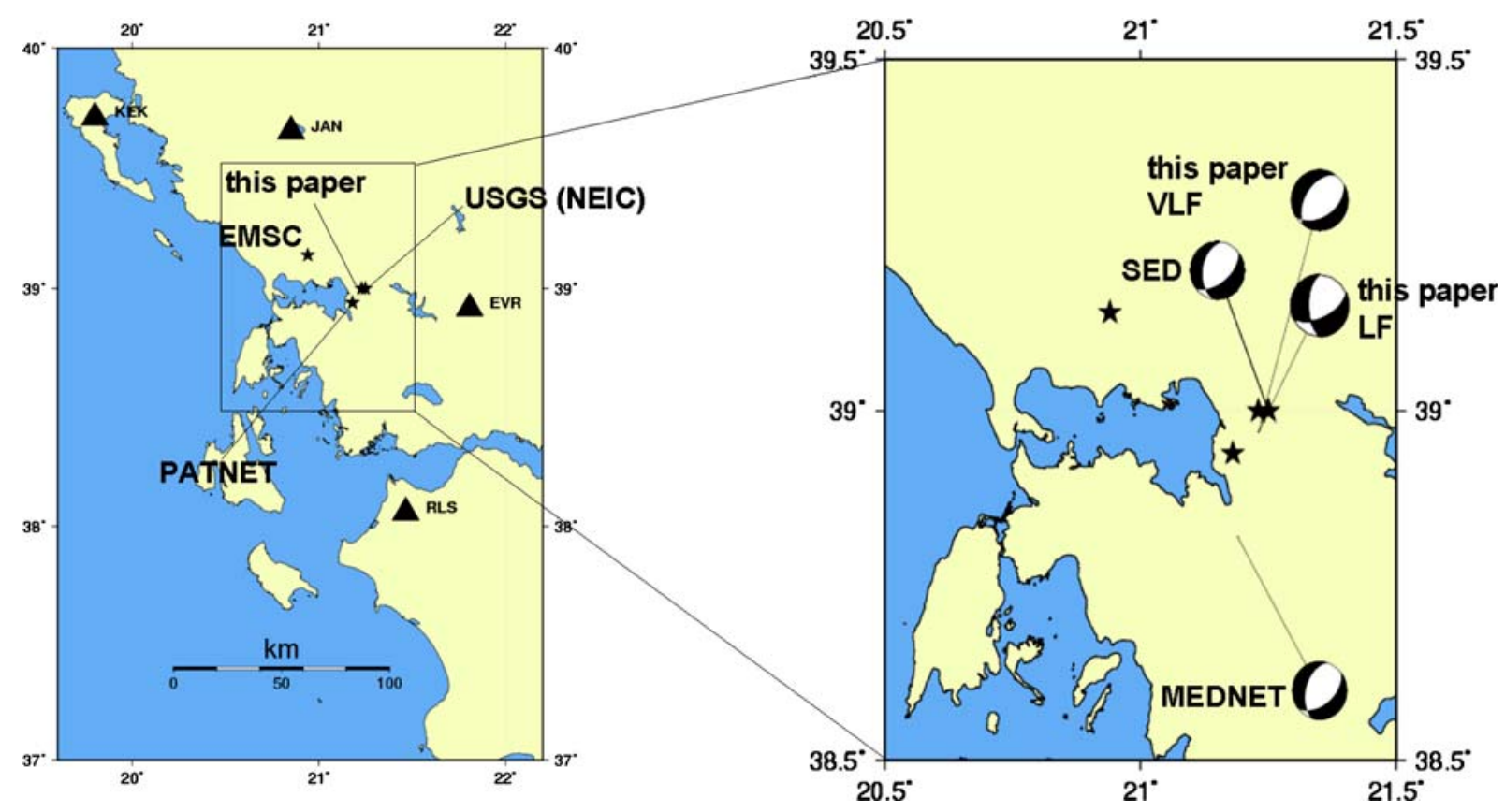

Fig. 1 The Amfilochia earthquake, western Greece. Left panel-broadband stations (triangles) and four different epicenter locations of the same event (stars). Right panelzoom with four fault-plane solutions; each bar with a

"beach ball" points to the respective centroid. "This paper $L F$ " represents the solution of Table 3 (top row), VLF of Table 5. The stars have the same meaning as in the left panel 
Table 2 Centroid moment-tensor solution reported by two agencies

\begin{tabular}{|c|c|c|c|c|c|c|c|c|c|}
\hline Agency & Lat. N (deg) & Lon. E (deg) & Depth $(\mathrm{km})$ & Strike (deg) & Dip (deg) & Rake (deg) & $\mathrm{M}_{0}\left(10^{16^{\circ}} \mathrm{Nm}\right)$ & $\mathrm{M}_{\mathrm{w}}$ & DC \% \\
\hline$\overline{\text { SED }}$ & 39.00 & 21.25 & 27 & 52 & 48 & -64 & 3.13 & 4.96 & 30 \\
\hline MEDNET & 38.82 & 21.19 & 27 & 61 & 58 & -47 & 2.40 & 4.9 & 61 \\
\hline
\end{tabular}

Large non-double-couple component of this earthquake expressed by the low DC\% values.

Sources: http://www.ingv.it/seismoglo/RCMT and http://www.seismo.ethz.ch/mt

$E=\sum\left(O_{i}-S_{i}\right)^{2}$, defined above, and the ratio $F=\frac{E(\text { model } 2)}{E(\operatorname{model} 1)}$ is compared with critical points of the $F$ distribution with $N-M$ dof, same for the nominator and the denominator in our case. Here, $M$ represents the number of parameters ( $M=5$ for the deviatoric model) and $N$ is the number of independent data points. Following Dreger and Woods (2002), we assume that in the studied period range $>10 \mathrm{~s}$, the investigated record-effective duration not larger than $70 \mathrm{~s}-$ represents seven independent samples; considering three components at four stations, the number of data is estimated as $N=84$. The 0.01 and 0.10 critical points of the $F$ distribution for the $N-M=79$ dof are $F_{0.01}=1.696$ and $F_{0.10}=1.336$, respectively.

\section{Waveform modeling of near-regional data}

The moment tensor calculation of this paper includes two steps. In step 1, we fix the horizontal source position (at the SED position, i.e., the USGS epicenter) and repeat the waveform inversion for a set of trial depths. The correlation between observed and synthetic seismograms, as a function of depth, is shown in Fig. 2, illustrating stability of the focal mechanism and the bestfitting depth of $17 \mathrm{~km}$. In step 2, we seek the centroid in three horizontal planes at the depth of 15,17 , and $19 \mathrm{~km}$, using a 25-point grid stencils, steps of $2 \times 2 \mathrm{~km}$, all centered below the epicenter. The grid search provides a weakly varying focal mechanism and an improved centroid position at the depth of $15 \mathrm{~km}$, horizontally shifted with respect to SED by $4 \mathrm{~km}$ to the west, and $4 \mathrm{~km}$ to the south (Fig. 3). A further refinement of the grid stencil did not change the result. The same was true when extending the grid search more in the southwest direction. The solution is given in the first row of Table 3. As seen from Fig. 1, the strike, dip, and rake angles are close to the agency values. It can be also documented by the $\mu$ values of the SED and MEDNET solutions, with respect
Fig. 2 The correlation between observed and synthetic waveforms and focal mechanism as a function of the trial source depth below the epicenter of SED. Colors represent the $\mathrm{DC} \%$

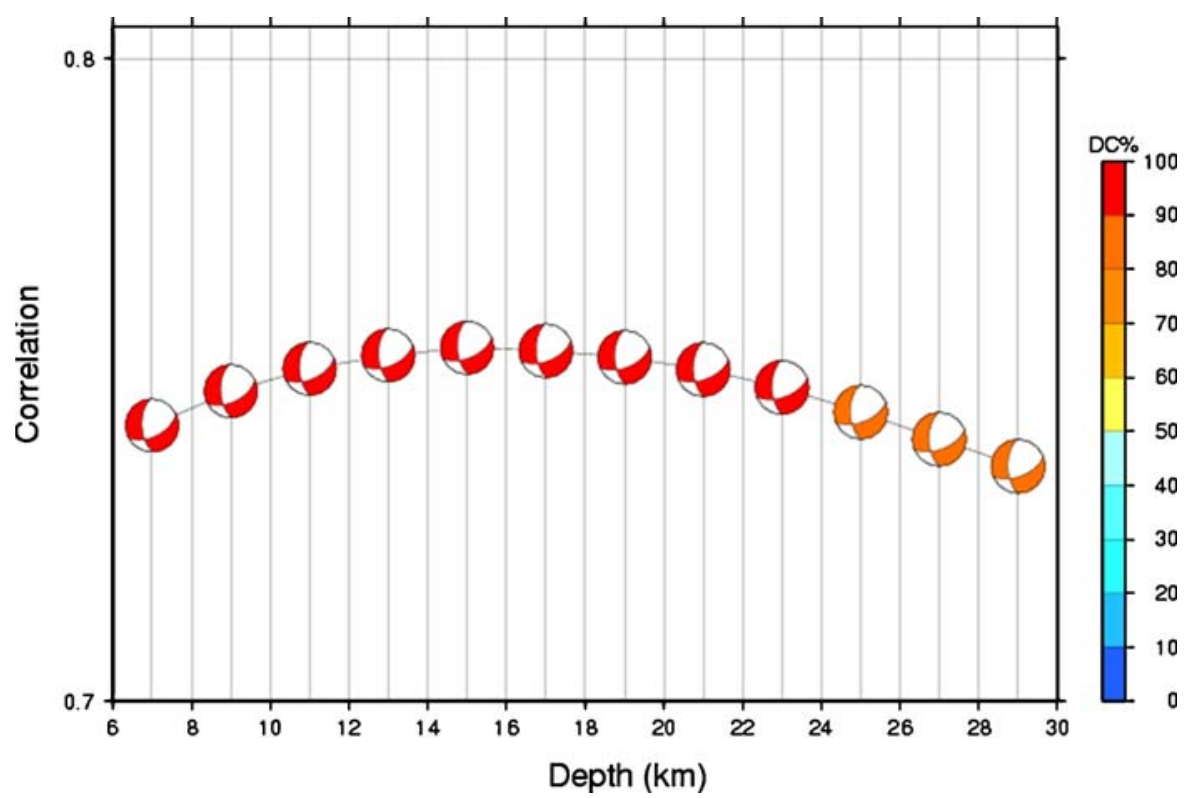


Fig. 3 Results of the moment-tensor calculation during the second step of the grid search at a grid of $2 \times$ $2 \mathrm{~km}$ increments in the West-East and South-North direction, the depth of $15 \mathrm{~km}$. The SED position is in the middle of the plot. The optimum solution is shown in red. The background represents the correlation between the observed and synthetic waveforms

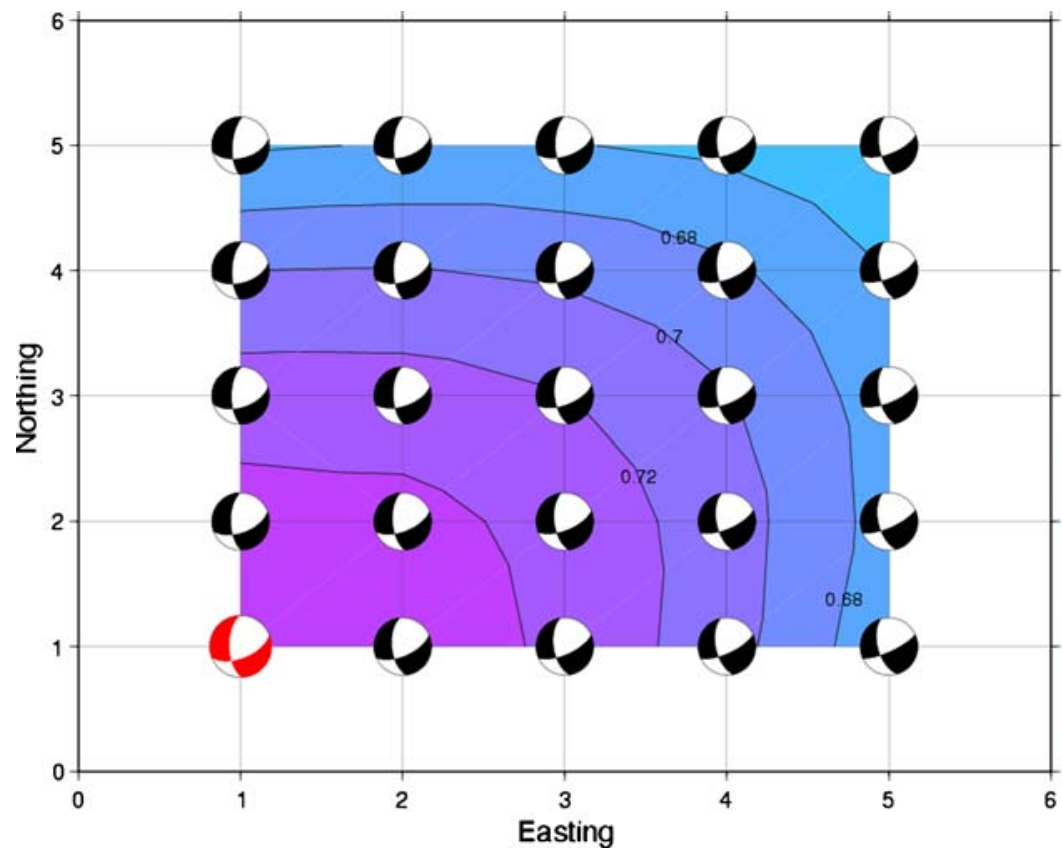

0.80
-0.78
-0.76
-0.74
-0.72
-0.70
-0.68
-0.66
-0.64
-0.62
-0.60 to our solution, 0.1 and 0.15 , respectively. Stability of the solution is checked by a jackknifing test; we repeatedly remove one station and recalculate the inversion (Table 4, Fig. 4).

To better understand the DC\% values, we inspect step 2 of the spatio-temporal grid-search results in more detail. While the strike, dip, and rake angles vary less than $15^{\circ}$ each (strike $60^{\circ}$ to $70^{\circ}$, dip $50^{\circ}$ to $65^{\circ}$, rake $-32^{\circ}$ to $-42^{\circ}$ ), the DC\% variations are quite dramatic. This can be seen from Fig. 5, where the DC\% is plotted against the correlation for each "point" of the studied spatiotemporal domain. The main variation of the $\mathrm{DC} \%$ comes from the temporal shifts; the DC\% can get practically any value from $0 \%$ to $100 \%$. The most meaningful DC\% values are those marked in Fig. 5 by red circles, corresponding to the largest correlation value at each spatial position, i.e., those for the optimum temporal shift (the centroid time). They provide the $\mathrm{DC} \%$ range of $73 \%$ to $100 \%$ related to the uncertainty of the optimum source position. The DC\% values reported by SED and MEDNET agencies are below this range.

To further check the relevance of the relatively high DC\% obtained from the near-regional stations, an experiment is made as follows: We inspect the MT solution at the optimum trial source position as a function of the source-time shift and 'move' from the optimum time (with DC\% = 93) to the nearest time where DC\% drops close to the SED value; it is a 2 -s shift and $\mathrm{DC} \%=31$. The strike-dip-rake angles obtained in that way $\left(65^{\circ}, 51^{\circ}\right.$, and $\left.-54^{\circ}\right)$ are not far from the agency

Table 3 The moment tensor solution of this paper $\left(<0.11^{\circ} \mathrm{Hz}\right)$

\begin{tabular}{llllllll}
\hline Sub-event & Time $(\mathrm{s})$ & Moment $\left(10^{16{ }^{\circ}} \mathrm{Nm}\right)$ & Strike $(\mathrm{deg})$ & Dip $(\mathrm{deg})$ & Rake $(\mathrm{deg})$ & DC \% & Var. red. \\
\hline 1 & 1.2 & 1.10 & 68 & 59 & -36 & 93 & 0.66 \\
2 & 4.6 & 0.47 & 135 & 63 & -62 & - & 0.68 \\
\hline
\end{tabular}

Time is the centroid time expressed with respect to the SED centroid time. Var. red. stands for the overall variance reduction. For a more detailed explanation of the DC\%, see the text. Subevents 1 and 2 have the common depth of $15 \mathrm{~km}$ and horizontal position $\left(\right.$ lat $=21.204^{\circ} \mathrm{E}$, lon $=38.964^{\circ} \mathrm{N}$ ), which is $4 \mathrm{~km}$ to the south and $4 \mathrm{~km}$ to the west with respect to the SED source horizontal position, i.e., the USGS epicenter. The DC\% of subevent 2 was not investigated. 
Table 4 Stability test for the source model composed of two DC subevents of the same spatial position

\begin{tabular}{|c|c|c|c|c|c|c|c|c|c|}
\hline Sub-event & $\mathrm{x}(\mathrm{km})$ & $\mathrm{y}(\mathrm{km})$ & Time (s) & $\mathrm{M}_{0}\left(10^{16^{\circ} \mathrm{Nm}}\right)$ & Strike (deg) & Dip (deg) & Rake (deg) & $\mathrm{DC} \%$ & Var. red. \\
\hline \multicolumn{10}{|l|}{ All stations } \\
\hline 1 & -4 & -4 & 1.2 & 1.10 & 68 & 59 & -36 & 93 & 0.66 \\
\hline 2 & -4 & -4 & 4.2 & 0.64 & 147 & 76 & -49 & - & 0.71 \\
\hline \multicolumn{10}{|c|}{ EVR removed } \\
\hline 1 & -4 & -6 & 1.4 & 1.06 & 63 & 57 & -38 & 89 & 0.71 \\
\hline 2 & -4 & -6 & 5.0 & 0.45 & 109 & 59 & -107 & - & 0.76 \\
\hline \multicolumn{10}{|c|}{ JAN removed } \\
\hline 1 & -2 & -8 & 1.4 & 0.88 & 66 & 56 & -40 & 95 & 0.60 \\
\hline 2 & -2 & -8 & 4.8 & 0.41 & 115 & 65 & -90 & - & 0.65 \\
\hline \multicolumn{10}{|c|}{ RLS removed } \\
\hline 1 & -4 & -8 & 1.0 & 0.93 & 69 & 72 & -29 & 94 & 0.69 \\
\hline 2 & -4 & -8 & 5.6 & 0.34 & 105 & 58 & -103 & - & 0.77 \\
\hline \multicolumn{10}{|c|}{ KEK removed } \\
\hline 1 & -4 & -8 & 1.0 & 1.13 & 75 & 65 & -26 & 86 & 0.67 \\
\hline 2 & -4 & -8 & 4.6 & 0.53 & 112 & 75 & -109 & - & 0.74 \\
\hline
\end{tabular}

It is the "delete-one" jackknifing, with the removed station indicated at the top of each sub-table. Depth was fixed to $15 \mathrm{~km}$. Horizontal position $\mathrm{x}(N>0), \mathrm{y}(E>0)$ is relative to the SED source position. Time is relative to the SED centroid time. Variance reduction was computed from all stations, including those removed from the inversion; the var. red. values given in second row of each sub-table is for the sum of both subevents.

solutions. Using this solution, we make forward simulation of the records and compare the waveform match with the previous solution of Table 3 $(\mathrm{DC} \%=93)$. The crustal model and frequency

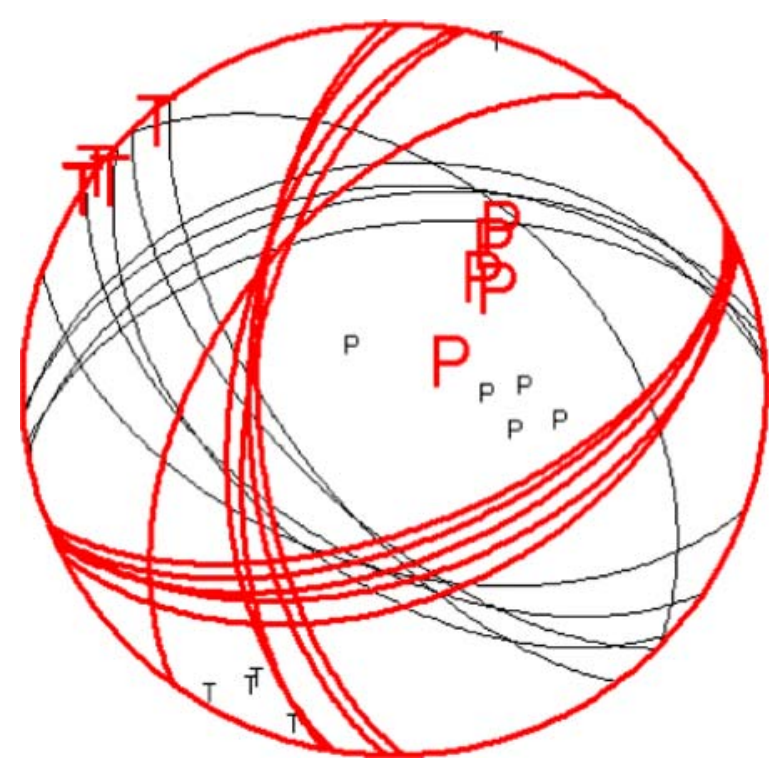

Fig. 4 Test of stability of the focal mechanism of the main shock; repeated inversions with removal of a station. Position of subevent 2 is fixed at the position of subevent 1 . Subevents 1 and 2 are shown in red and black, respectively range remain the same as above Haslinger et al. (1999). We find that the misfit of the DC\% $=93$ solution is lower, with statistical significance at the $99 \%$ level; $F=E(\mathrm{DC} \%=31) / E(\mathrm{DC} \%=93)=2.63$; $F>F_{0.01}=1.696$. The experiment demonstrated importance of the time shift for the DC\% estimate and clearly proved that the near-regional data strongly prefer an almost pure doublecouple source.

Can we better fit the data using exactly the moment tensor reported by the agencies? The answer is negative. To show this, we adopt the centroid positions and MT components from the agency reports and make the forward waveform modeling for the studied near-regional stations (Fig. 6). We find that the SED and MEDNET misfits are larger than in our model, $F=E$ (agency model)/ $E$ (our model $)=1.36$ and 1.38, for SED and MEDNET, respectively. It means that our solution is preferable, although at the $90 \%$ level only; $F>F_{0.10}=$ 1.336. Nevertheless, the near-regional data again do not require the low DC\%.

A partial conclusion is that based on this study and the two agency reports, with different crustal models, frequency ranges and with several estimates of the source position and time, we obtain a very stable estimate of the strike, dip, and 


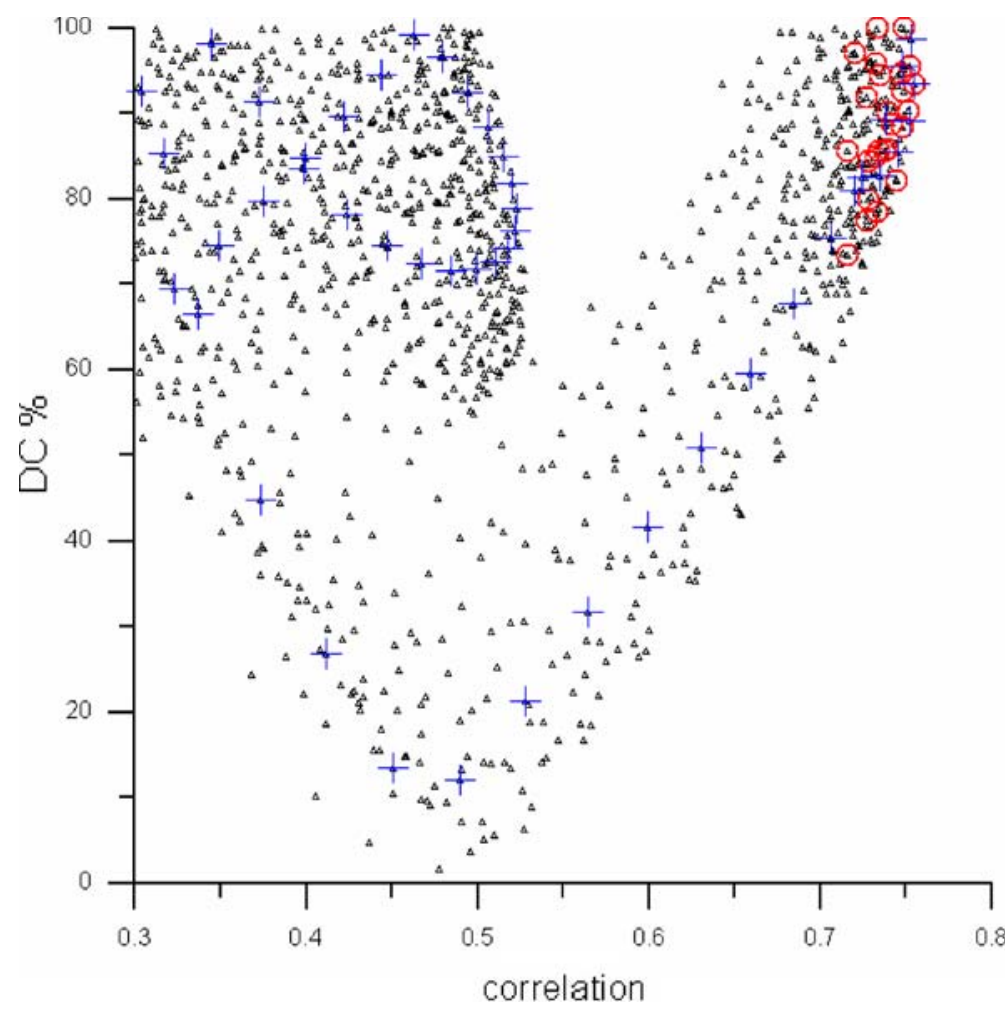

Fig. 5 The DC\% versus correlation plot. Each symbol corresponds to a 'point' in the studied spatio-temporal grid (a 25-point spatial grid stencil of the $2 \times 2 \mathrm{~km}$ step at the depth of $15 \mathrm{~km}$, and the temporal search from -4 to $16 \mathrm{~s}$ with the increment of $0.2 \mathrm{~s}$ ). Red circles belong to the largest correlation value at each spatial position, i.e., those

rake of the Amfilochia earthquake. The scalar moment of this paper is lower because of the preference of the shallower depth. On the other hand, the $\mathrm{DC} \%$ remains strongly variable. The examination of the DC\% change with spatial and temporal position of the source demonstrates how easy it is to fall into an apparently low DC\%, but all tests we performed show that the near-regional data interpreted with a single-point source prefer an almost pure double-couple event.

\section{Speculative model to explain apparently low DC\%}

If the near-regional data prefer the doublecouple source, then what is the origin of the low $\mathrm{DC} \%$ values reported by the agencies? Because for the optimum temporal shift. Note a strong variation of the $\mathrm{DC} \%$ with the correlation: the circles mark the range from $75 \%$ to $100 \%$. Even at the optimum spatial position of the source, the DC\% can get practically any value from $10 \%$ to $100 \%$ (the chain of blue symbols) if not carefully determining the centroid time

the agency solutions were obtained at very low frequencies, $<0.025 \mathrm{~Hz}$ (Bernardi et al. 2004; Pondrelli et al. 2006; Morelli et al. 2000), we try to build up a speculative source model able to explain simultaneously the low DC\% at the very low frequencies and the high $\mathrm{DC} \%$ at frequencies $<0.11 \mathrm{~Hz}$. The frequency dependence of the DC\% can be simulated by a complex source, featuring a temporal variation of the moment tensor. To investigate a possible source complexity we try to include a subevent 2 (the second row of Table 3). We assume the same position of both subevents, but allow a difference in their focal mechanism. As a result, we obtain a relatively large moment ratio subevent 2 /subevent 1 (around 0.4 ), the focal mechanism of subevent 2 is very different from subevent 1 , and the temporal separation between the subevents is of about $3.5 \mathrm{~s}$. Using $F$ test we find that adding second subevent 
Fig. 6 Comparison between the observed (top) and synthetic (bottom) seismograms in the frequency band 0.02-0.11 Hz. Synthetics are calculated by three methods: (1) for subevent 1 of Table 3 (black), for both subevents of Table 3 taken as $100 \%$ DC each (black dashed), and (2) for the source model of SED (red). Peak values of the normalized waveforms are displayed at right (in meters)
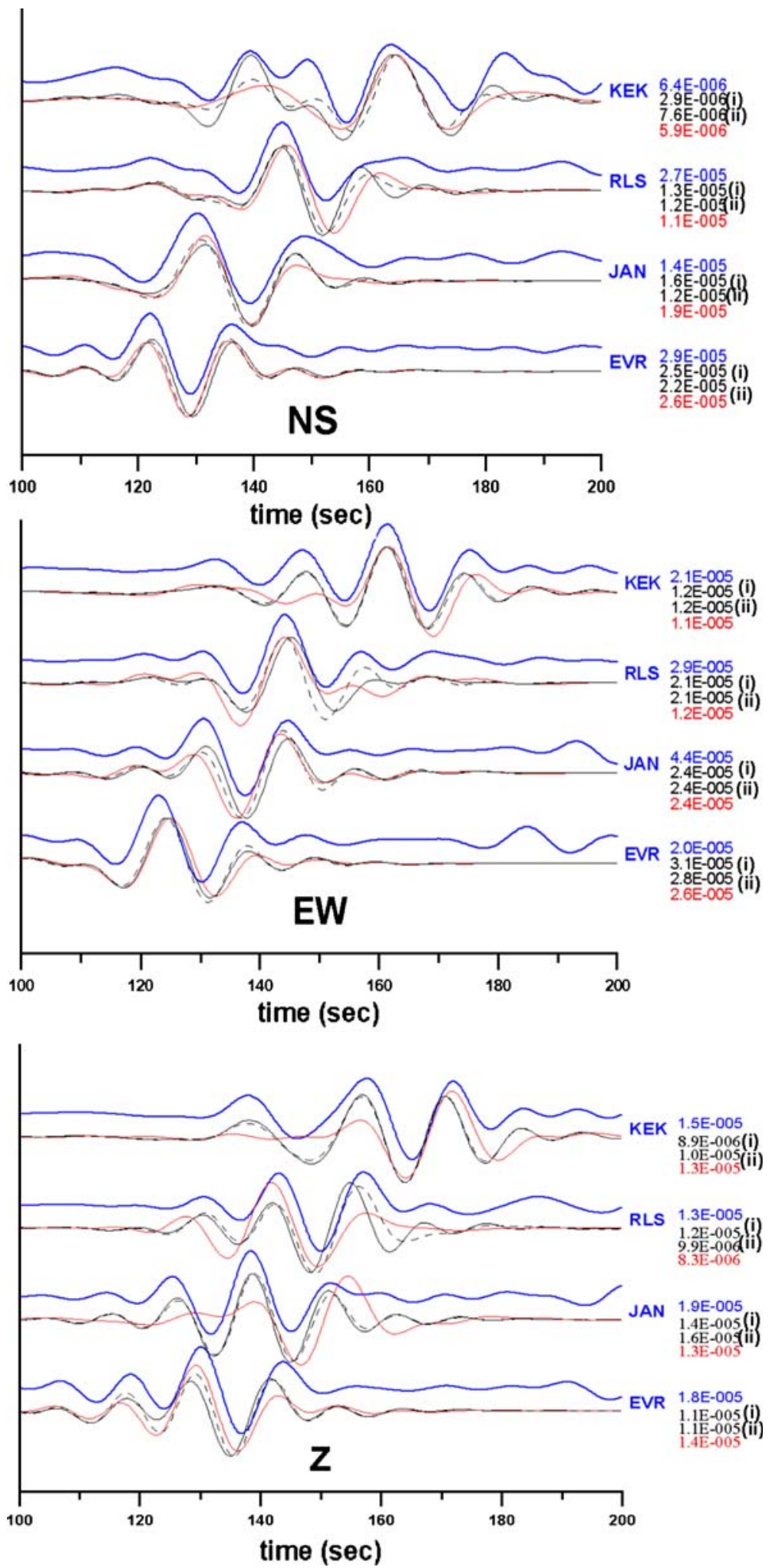
Table 5 The very low-frequency moment tensor solution $(<0.025 \mathrm{~Hz})$ derived from the synthetic data corresponding to the source model of Table 3, using both subevents with DC $=100 \%$

\begin{tabular}{|c|c|c|c|c|c|c|c|c|}
\hline$\underline{\text { Sub-event }}$ & Depth $(\mathrm{km})$ & Time $(\mathrm{sec})$ & Moment $\left(10^{\left.16^{\circ} \mathrm{Nm}\right)}\right.$ & Strike (deg) & Dip (deg) & Rake (deg) & DC \% & Var. red. \\
\hline 1 & 15.0 & 0.2 & 1.02 & 57 & 41 & -56 & 24 & 0.88 \\
\hline
\end{tabular}

The horizontal position of the centroid was constrained to be as in Table 3, the depth was free. Note the low value of the resulting DC\%.

represents an improvement of the waveform match, but significant at the $90 \%$ level only; $F=$ $E$ (single subevent) $/ E$ (two subevents) $=1.375$, $F>F_{0.10}=1.336$. The difference between the single-source and two-source synthetics is not large, but visible on seismograms (Fig. 6), basically as a small shift, "moving" the two-source synthetics slightly closer to the data. With the two sources of Table 3 the improvement with respect to the SED and MEDNET solution is already significant at the $99 \%$ level $(F=1.873$ and 1.897 , respectively; $\left.F>F_{0.01}=1.696\right)$. Repeated inversions with omission of one station prove stability of subevent 2 in terms of its seismic moment, the strike-dip-rake angles, as well as its temporal separation from subevent 1 (Table 4, Fig. 4).
An appealing feature of this speculative source model is its ability to explain the low DC\% values at very low frequencies. To show this, we make the following synthetic test. We take the two sources of Table 3, assume DC $\%=100$ for each, make the forward simulation at the stations studied in the present paper, and invert the synthetics in the very low frequency band of $0.005-0.025 \mathrm{~Hz}$. This is a great advantage of the synthetic model, since real data at our relatively near stations have no signal at this band. The solution (Table 5) is characterized by a single dominant subevent whose DC\% drops to $24 \%$, quite near the SED agency reports of Table $2(\mathrm{DC}=30 \%)$. Moreover, the stabilizing effect of the low-frequency range upon the DC\% estimate can be documented by the corresponding
Fig. 7 The DC\% versus correlation plot, similar to Fig. 5, but for the very low frequency inversion of the synthetics corresponding to the source model composed of two DC subevents $(\mathrm{f}<0.025 \mathrm{~Hz})$. Comparison with Fig. 5 shows the stabilizing effect of the lower frequencies upon the $\mathrm{DC} \%$

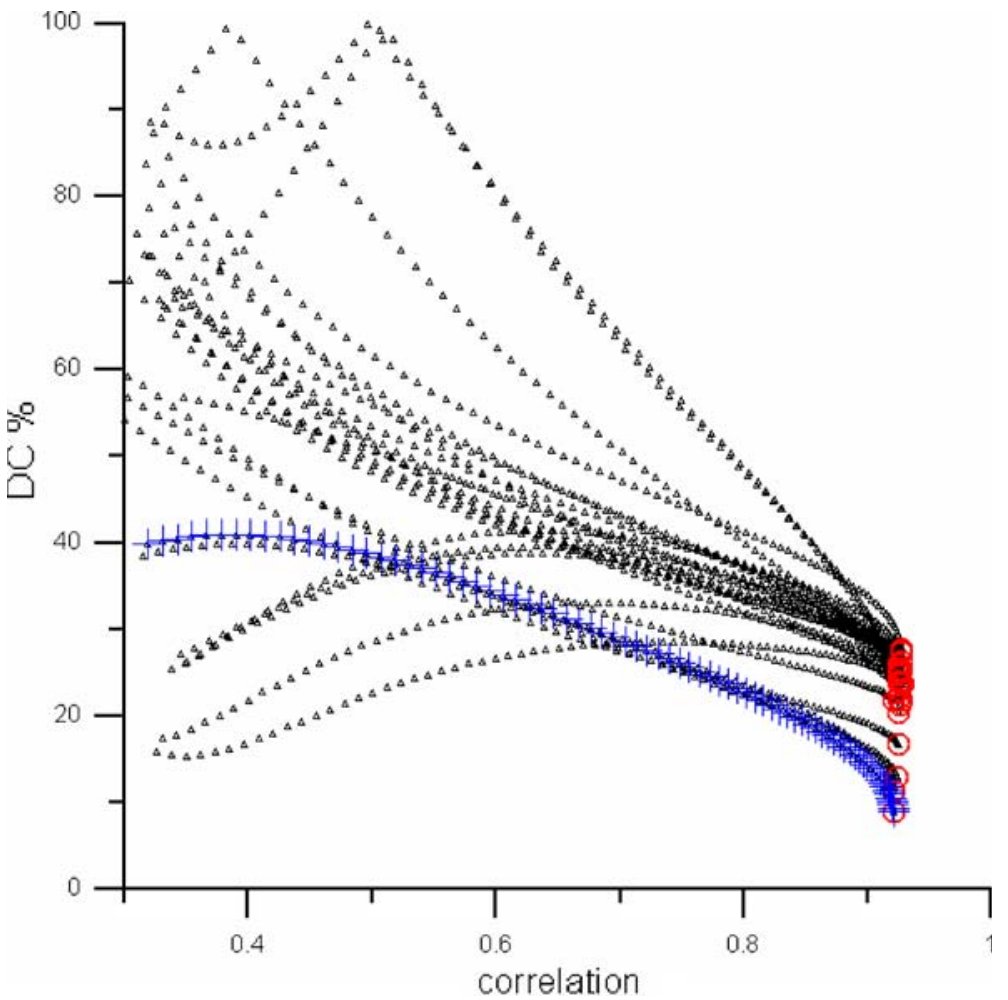


DC\% vs. correlation plot (Fig. 7). When repeating this experiment at the same frequency range, but with the centroid constrained at the SED position, the $\mathrm{DC} \%$ remains almost unchanged $(\mathrm{DC} \%=32)$, because the $\mathrm{DC} \%$ at this range is relatively stable. Similarly, we performed the same forward simulation with two subevents of Table 3 , but this time, we inverted the synthetics at the trial source position corresponding to the MEDNET centroid position. It led to the $\mathrm{DC} \%=49$, not far from MEDNET value, but different from SED due to their different centroid positions, similarly to the reported values.

The two-source model successfully reproduces the low DC\% reported at the very low frequencies, as well as unequal DC\% estimates with different source positions (SED and MEDNET). The low DC\% has an equivalent interpretation in terms the source complexity. It does not imply that the Amfilochia main shock actually consisted of two subevents, but it helps to understand how the low DC\% estimate might have been obtained. Indeed, comparing the synthetics of Fig. 6 constructed for subevent 1 and $1+2$, the essential difference is their apparent mutual shift, different at different stations. Therefore, when fitting real waveforms due to a single-point $100 \%$ DC source using imperfect structural model, and/or station(s) with imprecise absolute time, the source model accommodates to this situation by any of the two (equivalent) means: producing an apparent source complexity, or getting an apparent non-DC component at the very low frequencies.

\section{Conclusion and discussion}

Innovation of this paper has been in the confrontation of the low DC\% estimates of two seismic agencies with forward and inverse modeling of near-regional waveforms. For the Amfilochia earthquake, the waveform inversion from near-regional stations suggests a single-event source with a very high double couple percentage $(\mathrm{DC} \%=93)$, while the agency solutions provide the DC\% as low as 30 and 60 for SED and MEDNET, respectively. Using statistical $F$ test, forward modeling of the near-regional data with a single-event, low DC\% source model, gives a significantly worse waveform match.

Compared to the DC $\%=93$ single-event source model, the waveform match of near-regional data can be further improved (although at the 90\% significance level only) if considering a speculative two-event model. The two subevents are mutually separated by $3.5 \mathrm{~s}$ and differ very strongly in their focal mechanism. The same model, when viewed at the very-low frequency range, mimics behavior of the agency solutions: it provides the very low $\mathrm{DC} \%$, varying with the estimate of the source position.

Initially, in the early stage of this study, we believed that the Amfilochia earthquake actually consisted of two $100 \%$ DC subevents, representing a simplified description of the evolution of the source process-two main asperities of a heterogeneous slip distribution. However, since the two sources improve the fit compared to a single source at the $90 \%$ significance level only, and because it is difficult to accept a drastic difference in the focal mechanisms between subevent 1 and 2 and also because their temporal separation is much larger than an expected duration of a M5.5 event, we gave up such an interpretation.

Finally, we consider the two-source model as nothing but an interesting equivalent representation of the non-DC model, providing some insight into possible origin of the low DC\% of the agency reports: Comparing the single and two-source synthetics, their main difference is essentially in the mutual time shift (different shift at different stations). The agency solutions try to match all waveforms with optimum time alignment. Perfect fit is basically impossible due to unmodeled 3D structural features and/or inaccurate absolute time at a station(s). At very low-frequencies the unmodeled structural effect is generally considered not very important. Taking into account also the fact that for other earthquakes from the same region the SED agency does not systematically report the extremely low DC\% values, it is likely that the inaccurate time at a station(s) was the main reason of the strange behavior of the Amfilochia earthquake. It also agrees with the fact that SED reported surprisingly similar DC\% values also for two aftershocks of the Amfilochia earthquake (not dealt with in this paper), around 
$\mathrm{DC} \%=30$; and the same was true for MEDNET, around $\mathrm{DC} \%=60$. It indicates that an inaccurate absolute time at a station(s) jointly used for the main shock and the aftershocks might have likely caused the large apparent departure from the $100 \%$ DC mechanism.

We conclude that this paper provided two possible explanations of the Amifolochia earthquake: (1) The source featuring a strong nondouble-couple component, but at very low frequencies only, and with the DC\% highly variable with the assumed source position and time (SED versus MEDNET); an equivalent representation of such a single-event non-DC source is a two-event source model, consisting of two mutually shifted $100 \%$ DC subevents of highly different focal mechanism. (2) The source with a single $100 \%$ DC event; when speculating about likely reason why such an dual interpretation is possible, we assume that the apparently low DC\% reported by agencies arose from an inaccurate absolute time at a station(s). Since the waveform match of near-regional data only weakly prefers model (1), while it strongly rejects a single-event non-DC model, we conclude that the likely interpretation of the Amfilochia earthquake is model (2), an almost pure-shear event.

\begin{abstract}
Acknowledgements The paper significantly profited from constructive comments of the two anonymous reviewers and Prof. T. Dahm, Editor In Chief. The authors thank NOA-IG for waveforms. The GMT software of Wessel and Smith (1991) was used. This work was financially supported by the EC project 004043 (GOCE)3HAZ-CORINTH and the following projects in the Czech Republic: GAUK 279/2006/B-GEO/MFF, GACR 205/07/0502 and MSM 0021620860.
\end{abstract}

\section{References}

Bernardi F, Braunmiller J, Kradolfer U, Giardini D (2004) Automatic regional moment tensor inversion in the European-Mediterranean region. Geophys J Int 157:703-716

Bouchon M (1981) A simple method to calculate Green's functions for elastic layered media. Bull Seis Soc Am 71:959-971

Bruhn C (2003) Momententensoren hochfrequenter Ereignisse in Sudchile, Phd thesis. Mathematisch-
Naturwissenschaftliche Fakultat der Universitat Potsdam, Potsdam

Clinton JF, Hauksson E, Solanki K (2006) An evaluation of the SCSN moment tensor solutions: robustness of the $\mathrm{M}_{\mathrm{w}}$ magnitude scale, style and automation of the method. Bull Seis Soc Am 96:1689-1705

Dahm T, Manthei G, Eisenblaetter J (1999) Automated moment tensor inversion to estimate source mechanisms of hydraulically induced micro-seismicity in salt rock. Tectonophysics 306:1-17

Dreger D, Woods B (2002) Regional distance seismic moment tensors of nuclear explosions. Tectonophysics 356(1-3):139-156

Frohlich C (1994) Earthquakes with non-double-couple mechanisms. Science 264:804-809

Frohlich C (1995) Characteristics of well-determined nondouble-couple earthquakes in the Harvard CMT catalog. Phys Earth Planet Int 91:213-228

Hagos L, Shomali H, Roberts R (2006) Re-evaluation of focal depths and source mechanisms of selected earthquakes in the Afar depression. Geophys J Int 167: 297-308

Jechumtálová Z, Š́lený J (2001) Point-source parameters from noisy waveforms: error estimate by MonteCarlo simulation. Pure Appl Geophys 158:16391654

Julian BR, Foulger GR (2004) Microearthquake focal mechanisms - a tool for monitoring geothermal systems. Geotherm Res Council Bull 33:166-171

Julian BR, Miller AD, Foulger GR (1998) Non-doublecouple earthquake 1 . Theory. Rev Geophys 36: 525549

Kikuchi M, Kanamori H (1991) Inversion of complex body waves-III. Bull Seis Soc Am 81:2335-2350

Haslinger F, Kissling E, Ansorge J, Hatzfeld D, Papadmitriou E, Karakostas V, Makropoulos K, Kahle H-G, Peter Y (1999) 3D crustal structure from local earthquake tomography around the Gulf of Arta (Ionian region, NW Greece). Tectonophysics 304:201-218

Horálek J, Šílený J, Fischer T (2002) Moment tensors of the January 1997 earthquake swarm in NW Bohemia (Czech Republic): double-couple vs. nondouble-couple events. Tectonophysics 356:65-85

Melis NS, Konstantinou KI (2006) Real-time seismic monitoring in the Greek region: an example from the 17 October 2005 east Aegean sea earthquake sequence. Seismol Res Lett 77(3):364-370

Miller AD, Foulger GR, Julian BR (1998) Non-doublecouple earthquake 2. Observations. Rev Geophys 36:551-568

Morelli A, Ekstrom G, Mazza S, Pondrelli S, Boschi E, Dziewonski AM (2000) Surface-wave centroid moment tensors in the Mediterranean region: the MEDNET-Harvard project. Orfeus Newsletter, 2(1):4

Pasyanos ME, Dreger DS, Romanowicz B (1996) Toward real-time estimation of regional moment tensors. Bull Seism Soc Am 86:1255-1269

Pondrelli S, Salimbeni S, Ekström G, Morelli A, Gasperini P, Vannucci G (2006) The Italian CMT 
dataset from 1977 to the present. Phys Earth Planet Int 159:286-303

Roessler D (2006) Retrieval of earthquake source parameters in Inhomogeneous anisotropic media with application to swarm events in West Bohemia in 2000, Phd thesis. Department of Geosciences, University of Potsdam, Potsdam

Roessler D, Krueger F, Ruempker G (2007) Inversion for seismic moment tensors in anisotropic media using standard techniques for isotropic media. Geophys $\mathbf{J}$ Int 169:136-148

Rueda J, Mezcua J (2005) Near-real-time seismic momenttensor determination in Spain. Seism Res Lett 76: 455-465

Sarao A, Panza GF, Privitera E, Cocina O (2001) Nondouble-couple mechanisms in the seismicity preceding the 1991-1993 Etna volcano eruption. Geophys J Int 145:319-335

Sokos E, Zahradník J (2008) ISOLA - A Fortran code and a Matlab GUI to perform multiple-point source in- version of seismic data. Computers and Geosciences. doi:10.1016/j.cageo.2007.07.005

Tselentis G-A, Melis N, Sokos E, Papatsimpa K (1996) The Egion June 15, 1995 (6.2 ML) Earthquake, Western Greece, Pure Appl. Geophys. 147, 83-98

Vavryčuk V (2002) Non-double-couple earthquakes of 1997 January in West Bohemia, Czech Republic: evidence of tensile faulting. Geophys J Int 149:365374

Vavryčuk V (2004) Inversion for anisotropy from nondouble-couple components of moment tensors. J Geophys Res 109:B07306

Vavrycuk V (2007) On the retrieval of moment tensors from borehole data. Geoph Prospecting 55(3):381-391

Weber Z (2006) Probabilistic local waveform inversion for moment tensor and hypocentral location. Geophys J Int 165:607-621

Yunga S, Lutikov A, Molchanov O (2005) Non double couple seismic sources, faults interaction and hypothesis of self-organized criticality. NHESS 5:11-15 